\title{
Low Frequency Electromagnetic Radiation Effect Through the Ionosphere
}

\author{
Glushchenko AG*, Glushchenko EP and Glushchenko AA \\ Department of Physics Povolzhsky State University of Telecoimmunications and Informatics, Russia
}

*Corresponding author: Alexander Glushchenko AG, Department of Physics Povolzhsky State University of

Telecommunications and Informatics, Samara, Russia

\begin{abstract}
ARTICLE INFO
Received: 蔧 July 15, 2020

Published: 幽 July 28, 2020

Citation: Glushchenko AG, Glushchenko

ANNOTATION

The effect of the passage of electromagnetic waves of low frequencies through the ionosphere layer is considered. This is observed during the period of activity of its parameters and leads to the previously not considered effect of low-frequency cosmic radiation on natural processes of various nature on the Earth's surface. Anomalous processes on earth are directly related to the period of activation of the ionosphere parameters due to natural and technogenic factors.
\end{abstract} EP and Glushchenko AA. Low Frequency Electromagnetic Radiation Effect Through the Ionosphere. Biomed J Sci \& Tech Res 29(2)-2020. BJSTR. MS.ID.004762.
Keywords: Electro magnetic Waves; Ionosphere; Anormal Processes

\section{Introduction}

Today, the main problem is the not very successful fight against the virus pandemic. This is due to a lack of understanding of the causes of many anomalies in nature. The struggle of biologists and doctors with the consequences is important, but cannot solve the problem, but can only reduce the number of infected. We believe that the cause of many environmental disasters, or a purely external or (and) result of technogenic processes, is the reaction of the biosphere to electromagnetic radiation. Currently, constant interest is given to fluctuations in the thickness of the ozone layer surrounding the Earth and providing shielding from hard ultraviolet radiation $[1,2]$. Although the concentration of ozone in the ozone layer is very small, it is important for life because it absorbs biologically harmful ultraviolet (UV) radiation coming from the sun $[3,4]$. Studies have shown that the ozone layer is destroyed by chemicals released by industry. Concern that ultraviolet radiation is life threatening due to a decrease in the ozone layer, including the growth of oncology in humans and other environmental problems, has led to decisions banning the use of a number of chemicals.

This reduced the destruction of the ozone layer and its gradual recovery. It is believed [5] that low-frequency electromagnetic radiation (below plasma $\omega<\omega_{P}$ ) does not penetrate the layers of the ionosphere surrounding the Earth. The ionosphere is a "screen" for low-frequency emissions. This is confirmed by the effect of the propagation of short-wave radiation over long distances since the Earth's surface and the layer of the ionosphere form a kind of waveguide. Therefore, the influence of low-frequency cosmic radiation on processes on the surface of the earth is usually not considered, although the decisive role of electromagnetic radiation in biological processes is known [6-8]. Our studies [9] show that these ideas are erroneous and under certain conditions (indicated below) the ionosphere is not only permeable to low-frequency electromagnetic radiation, but also plays the role of an amplifier of electromagnetic influence.

For an isotropic plasma, this condition $\omega<\omega_{P}$ is known for the dielectric constant $\varepsilon=\varepsilon^{\prime}+i \varepsilon^{\prime \prime}$ where $\varepsilon^{\prime \prime}>0$.,Under real conditions, the ranges of transmission frequencies also depend on the magnitude and direction of the earth's magnetic field and differ for waves of different polarization [9]. The most important for living organisms are circular polarized waves, which actively interact with DNA, which has a spiral structure. The region of attenuation in the case of the dissipative nature of the plasma changes to the region of amplification in the case of the active nature of the plasma, even at low activity. This may explain the sudden occurrence of various types of anomalies, the cause of which may be the penetration from 
outer space of electromagnetic studies, which plays a major role in all processes occurring on the Earth's surface. Thus, anomalies are simply a response to electromagnetic influences coming from outer space. Their diversity is a consequence of the effects of various frequencies and spectrum distributions. The question about the frequency of change of ionospheric parameters.

Thus, the hypothesis for the cause of anomalous phenomena in nature (e.g., unexpected disease outbreaks, such as unexpected disappearance) can be external radiation, from which the ionosphere is a screen under normal conditions, but can "break" the electromagnetic radiation in the special conditions. These conditions for mankind can have natural (external) and man-made (internal) characters. Currently both of these reasons. In the past, these anomalies were worn periodically (sudden emergence and abrupt extinction of any catastrophic situation, plague, typhus, splash of populations of locusts, natural disasters). The type of disasters is directly linked to the type of frequency of exposure. Thus, it is necessary to expand measures already established to protect the ozone layer to a wider class of radiation, not only UV, but also low-frequency electromagnetic influences.

ISSN: 2574-1241

DOI: 10.26717/BJSTR.2020.29.004762

Glushchenko AG. Biomed J Sci \& Tech Res

CC) This work is licensed under Creative Commons Attribution 4.0 License

Submission Link: https://biomedres.us/submit-manuscript.php

\section{References}

1. Thangavel S, Siva K (2011) Ozone Layer Depletion and Its Effects: A Review. International Journal of Environmental Science and Development 2(1): 30-37.

2. Tabin S (2008) Global Warming: The Effect of Ozone Depletion. APH Publishing pp. 194.

3. Solomon S (2016) Emergence of healing in the Antarctic ozone layer. Science 353(6296): 269-274.

4. Narayanan DL, Saladi RN, Fox JL (2010) "Review: Ultraviolet radiation and skin cancer". International Journal of Dermatology 49(9): 978-986.

5. Kelley M (2009) Ionosphere of the Earth: Plasma Physics and Electrodynamics ( $2^{\text {nd }}$ edn). Academic Press. ISBN 9780120884254.

6. Purcell E, Maureen D (2013) Electricity and Magnetism. ( $3^{\text {rd }}$ Edn.), Cambridge University Press, New York, USA.

7. https://ehtrust.org/science/bees-butterflies-wildlife-researchelectromagnetic-fields-environment/.

8. Bystrov R, Potapov A, Cherepenin V, Dmitriev V, Perunov Y (2014) Electromagnetic systems and means of deliberate interference to physical and biological objects. Rensit 6(2): 129-169.

9. Glushchenko A, Zacharchenko E (2011) Stimulated transparency of transcendental structures. Lambert pp. 167.

$\begin{array}{ll}\text { BIOMEDICAL } & \text { Assets of Publishing with us } \\ \text { RESEARCHES } & \text { - Global archiving of articles } \\ & \text { - Immediate, unrestricted online access } \\ & \text { - Rigorous Peer Review Process } \\ & \text { - Anttps://biomedres.us/ }\end{array}$

